\title{
Cobalt nitride nanoflakes supported on Ni foam as a high- performance bifunctional catalyst for hydrogen production via urea electrolysis
}

\author{
YANMIN CHEN $^{\mathrm{a}}$, PEIJIAN SUN ${ }^{\mathrm{b}, *}$ and WEIWEI XING \\ ${ }^{a}$ College of Chemistry and Chemical Engineering, Zhengzhou Normal University, No. 6 Yingcai Street, \\ Zhengzhou 450044, China \\ ${ }^{\mathrm{b}}$ Zhengzhou Tobacco Research Institute of CNTC, No. 2 Fengyang Street, Zhengzhou 450001, China \\ ${ }^{\mathrm{c}}$ Faculty of General Education, Zhengzhou Technology and Business University, No. 8 Qiancheng Road, \\ Zhengzhou 451400, China \\ E-mail: pjsunztri@163.com
}

MS received 7 May 2019; revised 8 July 2019; accepted 11 July 2019

\begin{abstract}
Substituting low theoretical potential of the urea oxidation reaction (UOR) for the high theoretical potential of water splitting at the anode (oxygen evolution reaction) is meaningful for hydrogen energy storage and conversion. In this work, a bifunctional catalyst, cobalt nitride nanoflakes supported on Ni foam (CoN NF/NF), was synthesized for both UOR and hydrogen evolution reaction (HER). A two-electrode electrolyzer (CoN NF/NFIICoN NF/NF) was constructed. To drive $100 \mathrm{~mA} / \mathrm{cm}^{2}$, the voltage of CoN NF/ $\mathrm{NF} \| \mathrm{CoN} \mathrm{NF} / \mathrm{NF}$ only $1.698 \mathrm{~V}$ is required, which is much lower than that $\mathrm{Pt} / \mathrm{Cl} / \mathrm{IrO}_{2}(1.860 \mathrm{~V})$ and the current density can be maintained for $30 \mathrm{~h}$.
\end{abstract}

Keywords. UOR; bifunctional; catalyst; HER.

\section{Introduction}

The consumption of fossil fuels has led to an urgent need to develop sustainable clean energy to solve the energy crisis. ${ }^{1-5}$ Hydrogen energy as a rich resource, high energy, and green energy of no secondary pollution is considered to be the ideal energy source for replacing fossil energy. ${ }^{6}$ Currently, hydrogen evolution reaction (HER) from electrochemical water splitting represents an emerging key technology for long-term storage of electricity from renewable sources to reduce intermittent supply as one of the most efficient methods to produce hydrogen. ${ }^{7-10}$ However, oxygen evolution reaction (OER) as the anode of water splitting, has a high theoretical oxidation potential $(1.23 \mathrm{~V})$. This will greatly limit hydrogen production. $^{11-13}$ Therefore, the lower theoretical potential $(0.36 \mathrm{~V})$ of the urea oxidation reaction (UOR) is chosen to replace OER and non-toxic and non-polluting gases $\mathrm{N}_{2}$ and $\mathrm{CO}_{2}$ are produced in UOR, the reaction equation as follows: ${ }^{14}$
UOR: $\mathrm{CO}\left(\mathrm{NH}_{2}\right)_{2}+6 \mathrm{OH}^{-} \rightarrow \mathrm{N}_{2}+5 \mathrm{H}_{2} \mathrm{O}+\mathrm{CO}_{2}+6 \mathrm{e}$

$$
\begin{aligned}
& \text { HER: } 6 \mathrm{H}_{2} \mathrm{O}+6 \mathrm{e}^{-} \rightarrow 3 \mathrm{H}_{2}+6 \mathrm{OH}^{-} \\
& \text {Overall reaction: } \mathrm{CO}\left(\mathrm{NH}_{2}\right)_{2}+\mathrm{H}_{2} \mathrm{O} \\
& \quad \rightarrow \mathrm{N}_{2}+3 \mathrm{H}_{2}+\mathrm{CO}_{2}
\end{aligned}
$$

At the same time, water pollution caused by urine has become one of the most serious environmental problems. ${ }^{15-18}$ Urine mainly contains urea, which can be naturally converted into ammonia and nitrogen compounds, causing pollution to the atmospheric environment. ${ }^{19-21}$ The pollution issues by electrolysis of urea wastewater can be significantly improved. ${ }^{22-24}$ Thus, urea electrolysis has recently become the focus of attention. ${ }^{25-27}$ It not only can treat wastewater but also contributes to high efficient hydrogen production.

Furthermore, highly active catalysts to increase the efficiency of hydrogen evolution is required. Although UOR can be effectively catalyzed by the precious metals,

\footnotetext{
*For correspondence

Electronic supplementary material: The online version of this article (https://doi.org/10.1007/s12039-019-1678-6) contains supplementary material, which is available to authorized users.
} 

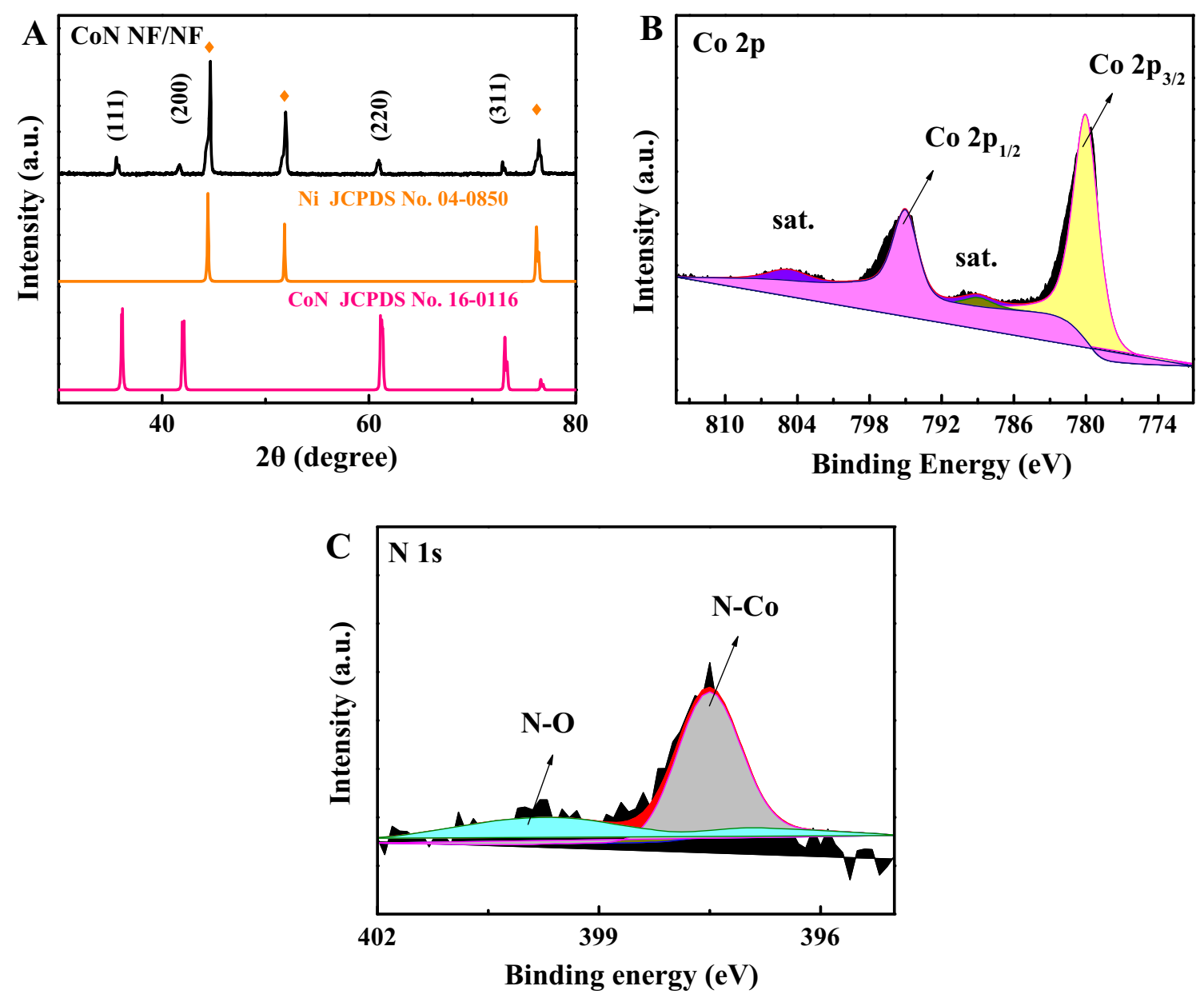

Figure 1. (A) XRD of CoN NF/NF. XPS of Co $2 p$ (B), N 1 s (C) for CoN NF/NF.

such as Pt or Rh. ${ }^{28,29}$ But their high cost makes it important to explore some low-cost and high-performance nonprecious metal materials. More recently, various nitride materials, such as titanium nitride ${ }^{30}$ and molybdenum nitride $^{31}$ have been proposed to be used in energy conversion and storage devices. Among them, particular interests are focused on $\mathrm{CoN}$, which has fast charge transfer due to the electron delocalization modulation. ${ }^{32} \mathrm{In}$ this work, the CoN nanoflakes on $\mathrm{Ni}$ foam (CoN NF/NF) was prepared. The first process was the synthesis of $\mathrm{CoO}$ nanoflakes on $\mathrm{Ni}$ foam ( $\mathrm{CoO} \mathrm{NF} / \mathrm{NF}$ ) through a hydrothermal method. The second process was the synthesis of $\mathrm{CoN} N F / N F$. The as-prepared $\mathrm{CoO}$ NF/NF above was placed in a ceramic crucible by a calcination method.

\section{Experimental}

\subsection{Materials}

Cobalt(II) chloride hexahydrate $\left(\mathrm{CoCl}_{2} \cdot 6 \mathrm{H}_{2} \mathrm{O}\right)$, Potassium hydroxide $(\mathrm{KOH})$, urea, and hexamethylenetetramine were all purchased from Sinopharm Chemical
Reagent Co. Ltd. (www.sinoreagent.com). $20 \mathrm{wt} \% \mathrm{Pt} / \mathrm{C}$ and $20 \mathrm{wt} \% \mathrm{IrO}_{2}$ were purchased from Shanxi Kaida Chemical Co. Ltd. (www.kd-chem.com). Nickel foam (NF) was purchased from Shenzhen Green and Creative Environmental Science and Technology Co. Ltd. All chemicals were used as received without further purification.

\subsection{Synthesis of CoN nanoflakes on Ni foam (CoN $N F / N F)$}

The first step was the synthesis of $\mathrm{CoO}$ nanoflakes on $\mathrm{Ni}$ foam $(\mathrm{CoONF} / \mathrm{NF}) .3 \mathrm{mmol} \mathrm{CoCl} 2 \cdot 6 \mathrm{H}_{2} \mathrm{O}$ and $10 \mathrm{mmol}$ hexamethylenetetramine were dissolved in $25 \mathrm{~mL}$ ultra-pure water under constant stirring. After that, the suspension and pretreated $\mathrm{Ni}$ foam were transferred to a $50 \mathrm{~mL}$ Teflon-lined autoclave and heated at $100{ }^{\circ} \mathrm{C}$ for $10 \mathrm{~h}$. The second step was the synthesis of CoN NF/NF. As the as-prepared $\mathrm{CoO} N F / N F$ above was placed in a ceramic crucible and calcined at $320^{\circ} \mathrm{C}$ for $2 \mathrm{~h}$ $\left(1{ }^{\circ} \mathrm{C} \mathrm{min}{ }^{-1}\right)$ under $\mathrm{NH}_{3}$ flow. 

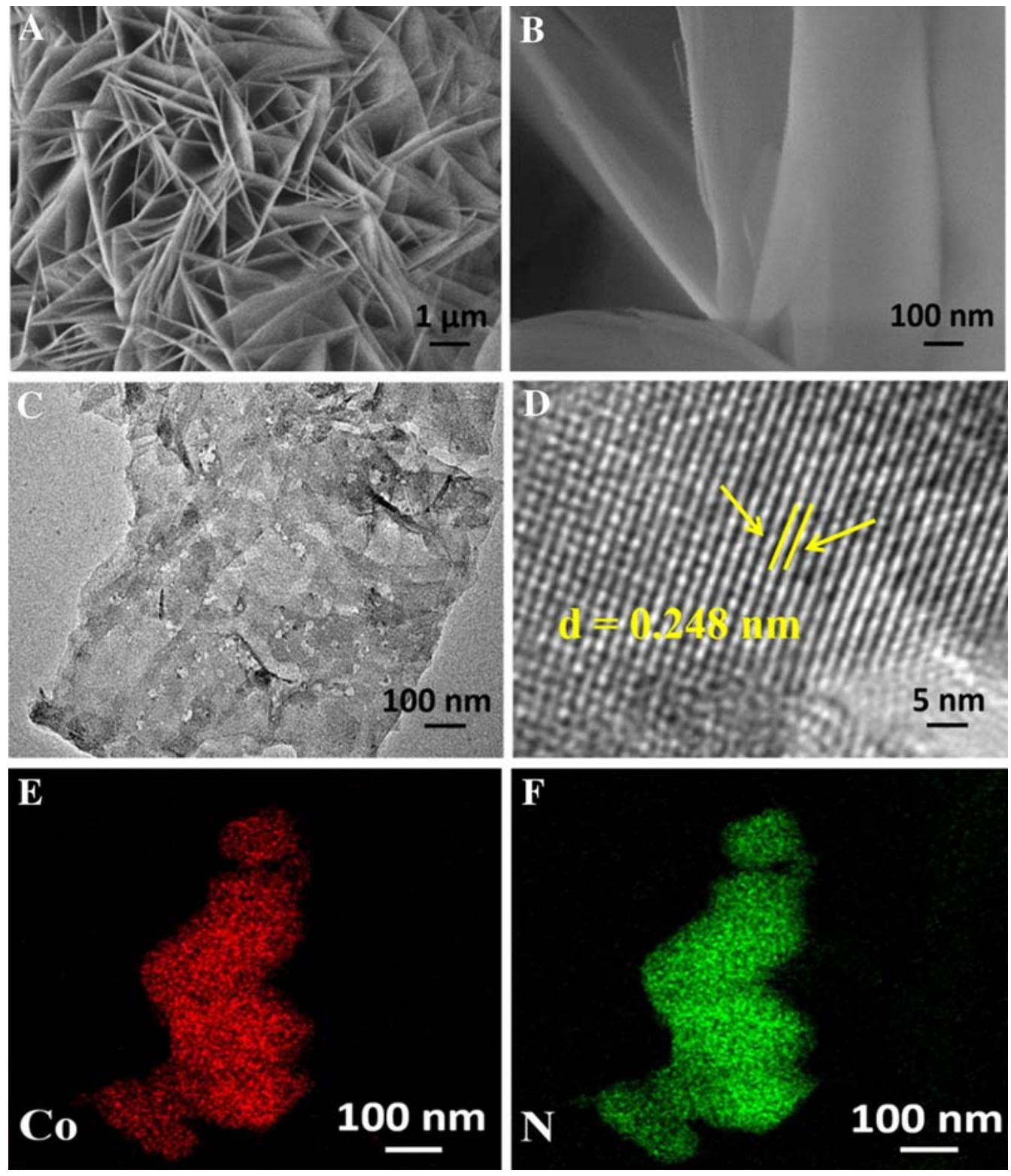

Figure 2. (A, B) SEM of CoN NF/NF. (C) TEM of CoN NF/NF. (D) HRTEM of CoN NF/NF. (E, F) Element mapping of CoN NF/NF.

\subsection{Physical characterization \\ and electrochemical measurements}

XRD data were acquired on a RigakuD/MAX 2550 diffractometer with $\mathrm{Cu} \mathrm{K} \alpha$ radiation $(\lambda=1.5418 \AA$ ). XPS measurements were performed on an ESCALABMK II X-ray photoelectron spectrometer using $\mathrm{Mg}$ as the exciting source. SEM measurements were carried out on an XL30 ESEM FEG scanning electron microscope at an accelerating voltage of $20 \mathrm{kV}$. TEM measurements were performed on a HITACHI H-8100 electron microscopy (Hitachi, Tokyo, Japan) with an accelerating voltage of $200 \mathrm{kV}$.
Electrochemical measurements were conducted on a CHI 660E electrochemical workstation with a standard three-electrode system. The prepared electrode materials were directly used as the working electrodes. The reference electrode was $\mathrm{HgO} / \mathrm{Hg}$ (MOE) and the counter electrode was graphite rod. All of the measured potentials were converted to a reversible hydrogen electrode (RHE) according to the Nernst equation $\left(\mathrm{E}_{\mathrm{RHE}}=\mathrm{E}_{\mathrm{Hg} / \mathrm{HgO}}+0.098+0.059 \mathrm{pH}\right)$. The electrolyte is $1 \mathrm{M} \mathrm{KOH}$ with $0.5 \mathrm{M}$ Urea. The electrochemical tests were measured at a scan rate of $5 \mathrm{mV} / \mathrm{s}$ under IR compensation. The electrochemical impedance spectroscopy (EIS) was conducted from frequency $(\mathrm{Hz}) 1$ to 1000000 . 

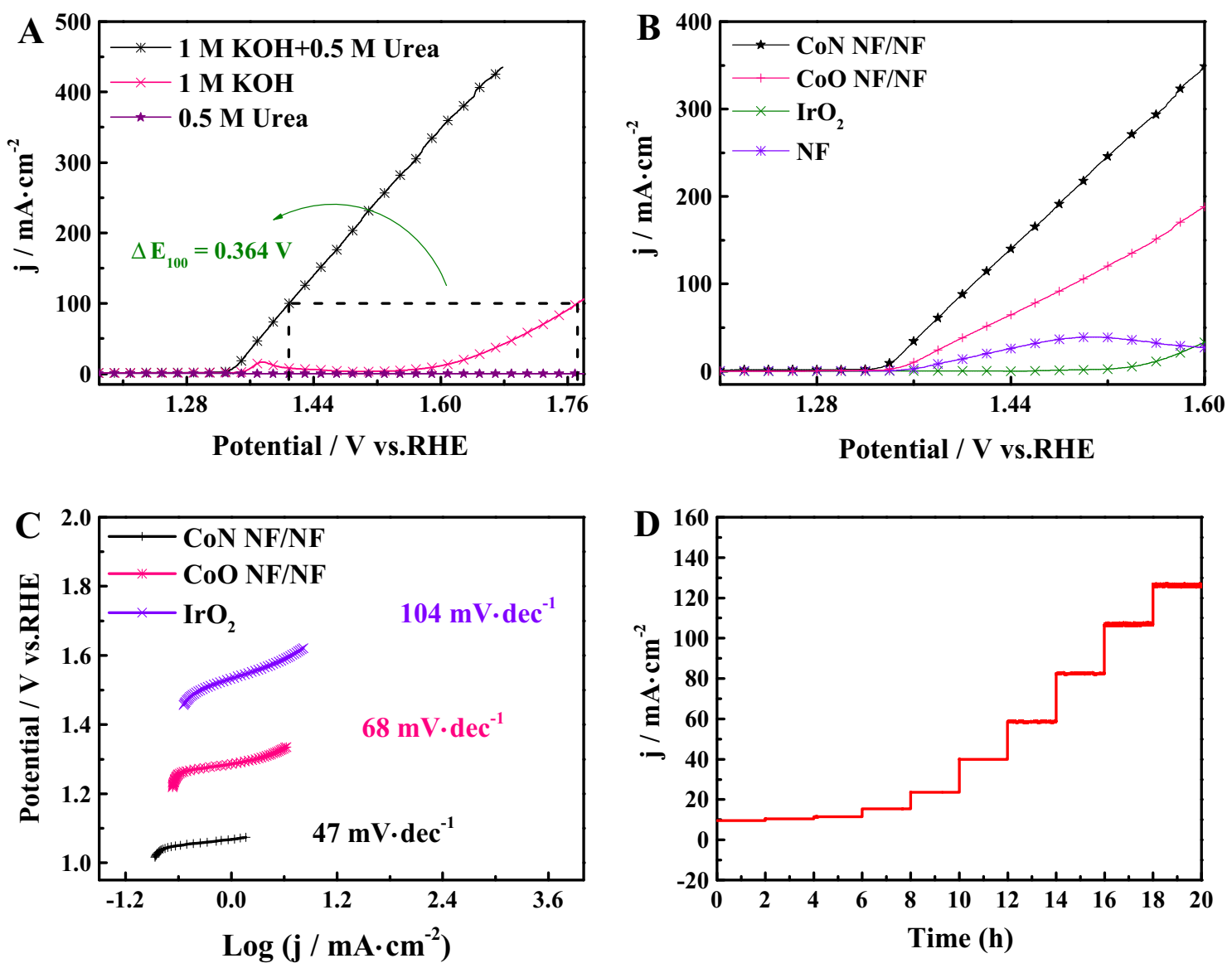

Figure 3. (A) LSVs of CoN NF/NF in different electrolytes. (B) LSVs and (C) Tafel slopes of CoN NF/NF, CoO NF/NF, $\mathrm{IrO}_{2}$ and NF. (D) Multi-voltage process of CoN NF/NF.

\section{Results and Discussion}

\subsection{Physical characterization}

The XRD pattern of CoN NF/NF was shown in Figure $1(\mathrm{~A})$. The diffraction peaks at $36.19^{\circ}, 42.19^{\circ}$, $61.34^{\circ}$, and $73.32^{\circ}$ corresponded to (111), (200), (220) and (311) crystal planes of CoN (JCPDS No. 16-0116), respectively. In addition, the peaks of $44.46^{\circ}, 51.77^{\circ}$ and $76.58^{\circ}$ have a good correspondence with Ni (JCPDS No. 04-0850). While high-temperature calcination is used due to the introduction of nitrogen in the synthesis process, this may cause the material to have residual stress leading to a slight shift in the diffraction. ${ }^{33,34}$ The results show that CoN NF/ NF was successfully synthesized. CoO NF/NF also has a good match with standard cards (Figure S1, Supplementary Information). To further confirm the surface chemical composition of the prepared catalysts, Figure 1(B) shows the XPS spectrum of Co $2 p$ for $\mathrm{CoN}$ NF/NF. The peak at $779.0 \mathrm{eV}$ is consistent with Co $2 p_{3 / 2}$, while the peak at $796.5 \mathrm{eV}$ can correspond to Co $2 p_{1 / 2} \cdot{ }^{35}$ Figure $1(\mathrm{C})$ reveals the XPS spectrum of $\mathrm{N}$ $1 \mathrm{~s}$ for $\mathrm{CoN} \mathrm{NF} / \mathrm{NF}$, the peaks at $397.5 \mathrm{eV}$ and
$399.9 \mathrm{eV}$ can be associated to $\mathrm{N}-\mathrm{Co}$ and $\mathrm{N}-\mathrm{O} .{ }^{36,37}$ Meanwhile, the chemical composition of $\mathrm{CoN}$ was measured in Table S1, Supplementary Information. The $\mathrm{C}, \mathrm{N}$, and $\mathrm{Co}$ atom \% were 50.26, 23.83 and $25.91 \%$ respectively.

The morphologies of the as-prepared catalysts were observed by SEM. The SEM images of CoN NF/NF show that the Ni foam (Figure S2(A), Supplementary Information) is uniformly grown with $\mathrm{CoN} N F / \mathrm{NF}$ nanoflakes (Figure 2(A)). It is clear that the CoN NF/NF is a fluffy and uniform layer structure (Figure 2(B)). $\mathrm{CoO} \mathrm{NF} / \mathrm{NF}$ also presents a sheet appearance (Figure S2(B), Supplementary Information). This indicates that CoN NF/NF nanoflakes with well-preserved morphology are successfully prepared after nitridation treatment. Figure 2(C) shows the TEM of CoN NF/NF. The sheet structure was clearly observed. As shown in Figure 2(D), the high-resolution transmission electron microscopy (HRTEM) of CoN NF/NF shows crystal stripes. Additionally, the inter lattice distances of $0.248 \mathrm{~nm}$ correspond to the CoN (111). This phenomenon is consistent with the conclusion obtained by $\mathrm{XRD}$. The elemental mappings demonstrate that the Co (Figure 2(E)) and $\mathrm{N}$ (Figure 2(F)) elements are 

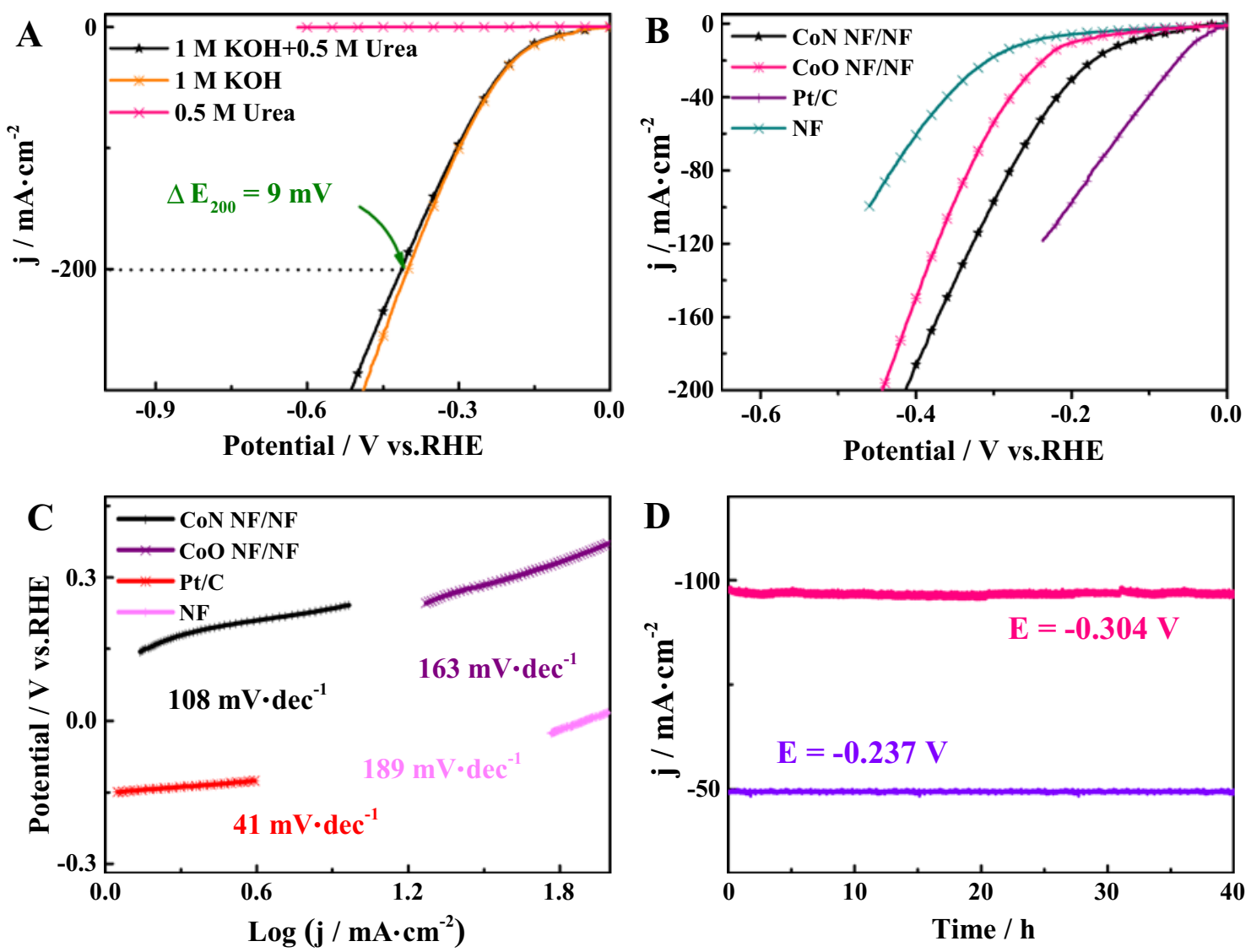

Figure 4. (A) LSVs of CoN NF/NF in different electrolytes. (B) LSVs and (C) Tafel slopes of CoN NF/NF, CoO NF/NF, $\mathrm{IrO}_{2}$ and NF. (D) Chronoamperometry testing (i-t) of CoN NF/NF.

uniformly distributed throughout the layer structure, confirming the successful fabrication of cobalt nitride nanoflakes on NF. All these observations support the formation of CoN nanoflakes on NF.

\subsection{Electrochemical characterization}

The catalytic UOR activities of CoN NF/NF (loading: $0.82 \mathrm{mg} / \mathrm{cm}^{2}$ ) were measured by electrochemical experiments and the most suitable urea concentration $(0.5 \mathrm{M})$ was selected by the polarization curve of the concentration gradient (Figure S3, Supplementary Information). LSVs of $\mathrm{CoN} \mathrm{NF} / \mathrm{NF}$ was tested in different electrolytes as shown in Figure 3(A). At $100 \mathrm{~mA} / \mathrm{cm}^{2}$, UOR electrode potential is $1.409 \mathrm{~V}$, which is $0.364 \mathrm{~V}$ lower than that of OER, which means UOR activity is better than that of OER. At $10 \mathrm{~mA} / \mathrm{cm}^{2}$, the potentials of $\mathrm{CoN} \mathrm{NF} / \mathrm{NF}, \mathrm{CoO} \mathrm{NF} /$ $\mathrm{NF}, \mathrm{IrO}_{2}$ and $\mathrm{NF}$ are $1.342,1.362,1.558$ and $1.641 \mathrm{~V}$, respectively as shown in Figure 3(B). Obviously, the potential of $\mathrm{CoN} N F / \mathrm{NF}$ is the lowest. This phenomenon can be considered as UOR activities of $\mathrm{CoN}$ NF/NF better than that of others. The Tafel slopes of
LSVs can be used to measure the electrode dynamics of the UOR. ${ }^{38}$ The Tafel slopes for CoN NF/NF, CoO $\mathrm{NF} / \mathrm{NF}$, and $\mathrm{IrO}_{2}$ are 47, 68, and $104 \mathrm{mV} / \mathrm{dec}$, respectively (Figure 3(C)). It is obvious that the Tafel slope of CoN NF/NF is the lowest, reflecting its fast kinetics and excellent UOR catalytic activity. ${ }^{39}$ Moreover, stability is vital to UOR. Figure 3(D) shows the multi-step chronopotentiometric curve of $\mathrm{CoN} \mathrm{NF} /$ NF. Specifically, a staircase potential is applied to CoN NF/NF electrode from $1.35 \mathrm{~V}$ up to $1.43 \mathrm{~V}$ with an increment of $8 \mathrm{mV}$ per $2 \mathrm{~h}$. At the current starting value, the potential immediately levels off and remains constant for the remaining $2 \mathrm{~h}$, especially at higher current. The fast chronopotentiometric response implies excellent mass transport. These results indicate that $\mathrm{CoN}$ NF/NF has excellent mass transportation, conductivity, and mechanical robustness (inward diffusion of $\mathrm{OH}$ and outwards diffusion of bubbles and fast response to current density in each potential change step). ${ }^{40,41}$ This measurement lasts for $20 \mathrm{~h}$ and after $3000 \mathrm{CV}$ cycles, it was observed that the current density can maintain $93.1 \%$ of the initial value (Figure S4, Supplementary Information). Meanwhile, the peaks from XRD are almost the same as those before 

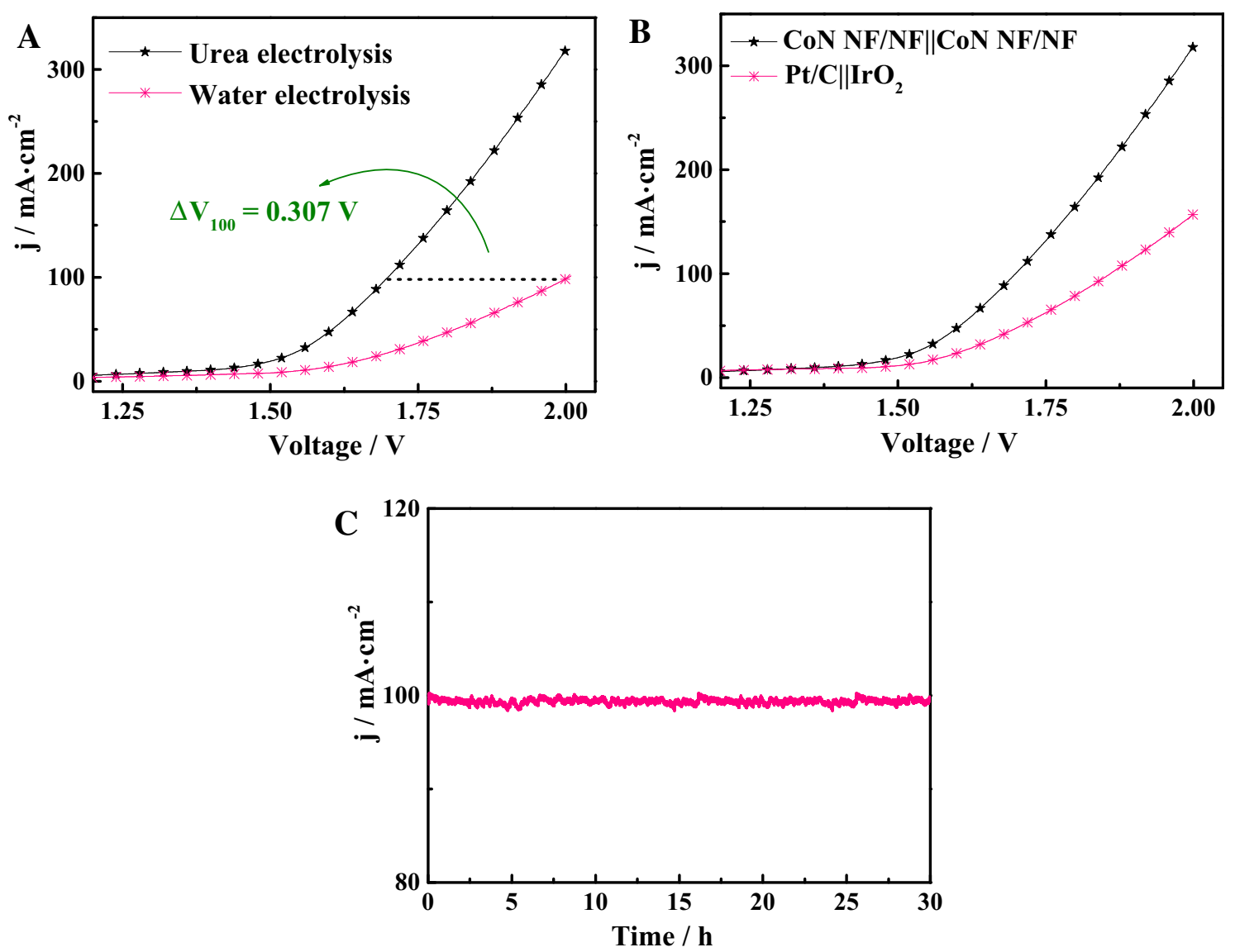

Figure 5. (A) LSVs of urea electrolysis and water electrolysis. (B) LSVs of $\mathrm{CoN} \mathrm{NF} / \mathrm{NF} \| \mathrm{CoN} \mathrm{NF} / \mathrm{NF}$ and $\mathrm{Pt} / \mathrm{ClIIO}_{2}$. (C) Chronoamperometric response of CoN NF/NFIICoN NF/NF.

$3000 \mathrm{CV}$ cycles, matches well with the standard cards (Figure S5, Supplementary Information). Those indicate the remarkable stability. ${ }^{25}$

To analyze the catalytic activities for HER, LSVs of CoN NF/NF was tested in different electrolytes (Figure 4(A)). The potential between electrolytes with and without urea at $200 \mathrm{~mA} / \mathrm{cm}^{2}\left(\Delta \mathrm{E}_{200}\right)$ is $9 \mathrm{mV}$. They have little difference, which indicates that urea has an insignificant effect on HER in $\mathrm{KOH}$. Figure 4(B) shows the LSVs of the as-prepared catalysts. At $10 \mathrm{~mA} / \mathrm{cm}^{2}$, the potentials of $\mathrm{CoN} \mathrm{NF/NF}$, $\mathrm{CoO} \mathrm{NF} / \mathrm{NF}, \mathrm{Pt} / \mathrm{C}$ and $\mathrm{NF}$ are 129, 198, 42 and $256 \mathrm{mV}$, respectively. Although the overpotential of $\mathrm{CoN} N F / \mathrm{NF}$ is higher than that of $\mathrm{Pt} / \mathrm{C}$, it is lower than that of $\mathrm{CoO} \mathrm{NF} / \mathrm{NF}$ and the impedance also shows the same conclusion (Figure S6, Supplementary Information). The Tafel slopes of $\mathrm{CoN}$ NF/NF, CoO NF/NF, $\mathrm{Pt} / \mathrm{C}$ and NF are 108, 163, 41 and $189 \mathrm{mV} / \mathrm{dec}$ (Figure 4(C)). Obviously, the Tafel slope of CoN NF/NF is the closest to $\mathrm{Pt} / \mathrm{C}$, indicating it performs efficiently for HER. As shown in Figure 4(D), chronoamperometry testing $(\mathrm{i}-\mathrm{t})$ of $\mathrm{CoN} \mathrm{NF} / \mathrm{NF}$ at -0.304 and $-0.237 \mathrm{~V}$ were performed. It shows that it can be stable for at least $40 \mathrm{~h}$.
To explore the electrochemical properties of the $\mathrm{CoN}$ $\mathrm{NF} / \mathrm{NF}$ electrode in overall urea oxidation, we performed a two-electrode electrolyzer using CoN NF/NF as anode and cathode (CoN NF/NF $\| \mathrm{CoN} \mathrm{NF} / \mathrm{NF})$. And $\mathrm{IrO}_{2}$ as cathode and $\mathrm{Pt} / \mathrm{C}$ as anode $\left(\mathrm{Pt} / \mathrm{C} \| \mathrm{IrO}_{2}\right)$ are used to compare. Figure 5(A) represents LSVs of CoN NF/ $\mathrm{NF} \| \mathrm{CoN} \mathrm{NF} / \mathrm{NF}$. The voltage of urea electrolysis is $1.698 \mathrm{~V}$, which is much lower than that of water electrolysis $(2.005 \mathrm{~V})$ at $100 \mathrm{~mA} / \mathrm{cm}^{2}$. This result demonstrates that urea electrolysis provides a significantly enhanced electrochemical performance when compared to water electrolysis. As shown in Figure 5(B), CoN NF/ NF $\| \mathrm{CoN} N F / N F$ needs voltages of 1.506 and $1.605 \mathrm{~V}$ at 20 and $50 \mathrm{~mA} / \mathrm{cm}^{2}$. While $\mathrm{Pt} / \mathrm{C} \| \mathrm{IrO}_{2}$ needs much higher value of 1.580 and $1.708 \mathrm{~V}$. This result demonstrates that the performance of $\mathrm{CoN} \mathrm{NF} / \mathrm{NF} \| \mathrm{CoN} \mathrm{NF} / \mathrm{NF}$ electrolyzer is much higher than that of $\mathrm{Pt} / \mathrm{C} \| \mathrm{IrO}_{2}$. Meanwhile, the electrochemical properties of the materials in the literature were compared. The results show that $\mathrm{CoN}$ has better catalytic activity than others (Figure S7 and Table S2, Supplementary Information). Furthermore, chronoamperometry (i-t) measurement performed at an applied voltage of $1.7 \mathrm{~V}$ on urea electrolysis shows that CoN NF/NF\|CoN NF/NF can sustain 
a high current density over $30 \mathrm{~h}$ of operation (Figure 5(C)), demonstrating its high stability.

\section{Conclusions}

In summary, a simple and low-cost method is used to synthesize non-noble $\mathrm{CoN}$ nanoflakes catalyst supported on nickel foam (CoN NF/NF) for efficient urea electrolysis to produce hydrogen energy. When this catalyst CoN NF/NF is used as both the anode and cathode materials in a urea electrolyser, it exhibits excellent catalytic activity and long-term stability towards both HER and UOR. The potential of CoN NF/ $\mathrm{NF}$ is $1.342 \mathrm{~V}$ at $10 \mathrm{~mA} / \mathrm{cm}^{2}$ on UOR. Such CoN NF/ NF also exhibits high activity toward HER, which only needs $129 \mathrm{mV}$ to achieve $10 \mathrm{~mA} / \mathrm{cm}^{2}$. Those enable CoN NF/NF to be a bifunctional electrocatalytic material for UOR and HER. The corresponding two-electrode electrolyzer (CoN NF/NFIICoN NF/NF) can drive $20 \mathrm{~mA} / \mathrm{cm}^{2}$ at $1.506 \mathrm{~V}$, which are $0.145 \mathrm{~V}$ and $0.074 \mathrm{~V}$ less than that of water electrolysis and $\mathrm{Pt} / \mathrm{C} \| \mathrm{IrO}_{2}$. This result shows a promising alternative to precious metals used in electrolytic hydrogen production. CoN NF/ $\mathrm{NF} \| \mathrm{CoN} \mathrm{NF} / \mathrm{NF}$ can maintain electrolysis for at least $20 \mathrm{~h}$ at $100 \mathrm{~mA} / \mathrm{cm}^{2}$, which implies it has excellent stability. Therefore, urea electrolysis is more efficient than electrolysis of water and the high activity and stability of the bifunctional catalyst should have high potential to replace precious metals for hydrogen production and treatment of industrial wastewater containing urea. This study provides a new idea to produce hydrogen using transition metal nitride nanoarrays.

\section{Supplementary Information (SI)}

Additional physical characterization and electrochemical tests and comparison tables of catalytic performance with some catalysts in recent literature. Supplementary Information is available at www.ias.ac.in/chemsci.

\section{Acknowledgements}

This work was funded by the Environmental Catalysis Innovative Research Team of Zhengzhou Normal University (No. 702010).

\section{References}

1. Anantharaj S, Ede S R, Karthick K, Sam Sankar S, Sangeetha K, Karthik P E and Kundu S 2018 Precision and correctness in the evaluation of electrocatalytic water splitting: revisiting activity parameters with a critical assessment Energ. Environ. Sci. 11744
2. Mota F M, Choi C H and Boppella R 2019 Arising synergetic and antagonistic effects in the design of Niand Ru-based water splitting electrocatalysts J. Mater. Chem. A 7639

3. Ojha K, Banerjee S and Ganguli A K 2017 Facile charge transport in $\mathrm{FeN}_{\mathrm{x}} / \mathrm{Mo}_{2} \mathrm{~N} / \mathrm{CNT}$ nanocomposites for efficient hydrogen evolution reactions J. Chem. Sci. 129989

4. Tilak B V, Ramamurthy A C and Conway B E 1986 High performance electrode materials for the hydrogen evolution reaction from alkaline media Chem. Sci. 97359

5. Manoharan R 1997 Electrochemical hydrogen evolution on solid oxides $\mathrm{RuO}_{2}, \mathrm{Ru}_{0.7} \mathrm{Rh}_{0.3} \mathrm{O}_{2}$, and $\mathrm{IrO}_{2}$, from acidic water Chem. Sci. 1091

6. Yan X, Tian L, He M and Chen X 2015 Three-dimensional crystalline/amorphous $\mathrm{Co} / \mathrm{Co}_{3} \mathrm{O}_{4}$ core/shell nanosheets as efficient electrocatalysts for the hydrogen evolution reaction Nano. Lett. 156015

7. Xu K, Chen P, Li X, Tong Y, Ding H, Wu X, Chu W, Peng Z, Wu C and Xie Y 2015 Metallic nickel nitride nanosheets realizing enhanced electrochemical water oxidation J. Am. Chem. Soc. 1374119

8. Pulipaka S, Koushik A K S and Deepa M 2019 Enhanced photoelectrochemical activity of Co-doped $\beta$-In2S3 nanoflakes as photoanodes for water splitting RSC Adv. 91335

9. Wang J, Cui W, Liu Q, Xing Z, Asiri A M and Sun X 2016 Recent progress in cobalt-based heterogeneous catalysts for electrochemical water splitting $A d v$. Mater. 28215

10. Xu W, Zhang H, Li G and Wu Z 2014 Nickel-cobalt bimetallic anode catalysts for direct urea fuel cell Sci. Rep. 458

11. Hu S, Feng $\mathrm{C}$, Wang $\mathrm{S}$, Liu J, Wu H, Zhang $\mathrm{L}$ and Zhang $\mathrm{J} 2019 \mathrm{Ni}_{3} \mathrm{~N} / \mathrm{NF}$ as bifunctional catalysts for both hydrogen generation and urea decomposition ACS Appl. Mater. Inter. 1113168

12. Ma M, Qu F, Ji X, Liu D, Hao S, Du G, Asiri A M, Yao Y, Chen L and Sun X 2017 Bimetallic nickel-substituted cobalt-borate nanowire array: an earth-abundant water oxidation electrocatalyst with superior activity and durability at near neutral pH Small 131700394

13. Gwak J, Choun M and Lee J 2016 Alkaline ammonia electrolysis on electrodeposited platinum for controllable hydrogen production ChemSusChem 9403

14. Chen S, Duan J, Vasileff A and Qiao S Z 2016 Size fractionation of two-dimensional sub-nanometer thin manganese dioxide crystals towards superior urea electrocatalytic conversion Angew Chem. Int. Ed. Engl. 553804

15. Fei J B, Cui Y, Yan X H, Qi W, Yang Y, Wang K W and $\mathrm{Li} \mathrm{J}$ B 2008 Controlled preparation of $\mathrm{MnO}_{2}$ hierarchical hollow nanostructures and their application in water treatment Adv. Mater. 20452

16. Barakat N A M, Alajami M, Alhaj Y, Obaid M and AlMeer S 2017 Enhanced onset potential NiMn-decorated activated carbon as effective and applicable anode in urea fuel cells Catal. Commun. 971304

17. Ding R, Qi L, Jia M and Wang H 2014 Facile synthesis of mesoporous spinel $\mathrm{NiCo} 2 \mathrm{O} 4$ nanostructures as highly efficient electrocatalysts for urea electro-oxidation Nanoscale 61369 
18. Tyagi M, Tomar M and Gupta V 2013 NiO nanoparticle-based urea biosensor Biosens. Bioelectron. 41110

19. Ji R Y, Chan D S, Jow J J and Wu M S 2013 Formation of open-ended nickel hydroxide nanotubes on threedimensional nickel framework for enhanced urea electrolysis Electrochem. Commun. 2921

20. Wu M S, Ji R Y and Zheng Y R 2014 Nickel hydroxide electrode with a monolayer of nanocup arrays as an effective electrocatalyst for enhanced electrolysis of urea Electrochim. Acta 114194

21. Yue Z, Yao S, Li Y, Zhu W and Zhang W 2018 Surface engineering of hierarchical $\mathrm{Ni}(\mathrm{OH})_{2}$ nanosheet@ nanowire configuration toward superior urea electrolysis Electrochim. Acta 268211

22. Wang L, Li M, Huang Z, Li Y, Qi S, Yi C and Yang B 2014 Toward high capacity and stable manganesespinel electrode materials: A case study of Ti-substituted system J. Power Sources 264282

23. Yan X, Tian L and Chen X 2015 Crystalline/amorphous $\mathrm{Ni} / \mathrm{NiO}$ core/shell nanosheets as highly active electrocatalysts for hydrogen evolution reaction $J$. Power Sources 300336

24. Liu Q, Xie L, Qu F, Liu Z and Du G 2017 Porous $\mathrm{Ni}_{3} \mathrm{~N}$ nanosheets array as a high-performance nonnoblemetal catalyst for urea-assisted electrochemical hydrogen production Inorg. Chem. Front. 20171120

25. Chen T, Liu D, Lu W, Wang K, Du G, Asiri A M and Sun X 2016 Three-dimensional Ni\r 2\r P nanoarray: an efficient catalyst electrode for sensitive and selective nonenzymatic glucose sensing with high specificity Anal. Chem. 887885

26. Wu M, Jao C, Chuang and Chen F 2017 Carbon-encapsulated nickel-iron nanoparticles supported on nickel foam as a catalyst electrode for urea electrolysis Electrochim. Acta 227210

27. Wang X, Wang J, Sun X, Wei S, Cui L, Yang W and Liu J 2017 Hierarchical coral-like NiMoS nanohybrids as highly efficient bifunctional electrocatalysts for overall urea electrolysis Nano Res. 11988

28. Chen S, Duan J, Vasileff A and Qiao S Z 2016 Size fractionation of two-dimensional sub-nanometer thin manganese dioxide crystals towards superior urea electrocatalytic conversion Angew. Chem. Int. Ed. 55 3804

29. Miller A T, Hassler B L and Botte G G 2012 Rhodium electrodeposition on nickel electrodes used for urea electrolysis J. Appl. Electrochem. 42925

30. Li F, Ohnishi R, Yamada Y, Kubota J, Domen K, Yamada A and Zhou H 2013 Carbon supported TiN nanoparticles: an efficient bifunctional catalyst for nonaqueous $\mathrm{Li}-\mathrm{O}_{2}$ batteries Chem. Commun. 491175

31. Dong S, Chen X, Zhang K, Gu L, Zhang L, Zhou X, Li L, Liu Z, Han P, Xu H, Yao J, Zhang C, Zhang X, Shang C, Cui G and Chen L 2011 Molybdenum nitride based hybrid cathode for rechargeable lithium- $\mathrm{O}_{2}$ batteries Chem. Commun. 4711291

32. Kang J S, Kim J Y, Yoon J, Kim J, Yang J, Chung D Y and Sung Y E 2018 Room-temperature vapor deposition of cobalt nitride nanofilms for mesoscopic and perovskite solar cells Adv. Energy Mater. 81703114

33. Gelfi M, Bontempi E, Roberti R, Armelao L and Depero L E 2004 Residual stress analysis of thin films and coatings through XRD ${ }^{2}$ experiments Thin Solid Films 450143

34. Song X, Chardonnet S, Savini G, Zhang S Y, Vorster W J J and Korsunsky A M 2008 Experimental/Modelling Study of Residual Stress in Al/SiCp Bent Bars by Synchrotron XRD and Slitting Eigenstrain Methods. Mater. Sci. Forum 571277

35. Tong Y, Chen P, Zhou T, Xu K, Chu W, Wu C and Xie Y 2017 A bifunctional hybrid electrocatalyst for oxygen reduction and evolution: cobalt oxide nanoparticles strongly coupled to B, N-Decorated Graphene Angew. Chem. Int. Ed. 1297227

36. Liu T, Li M, Dong P, Zhang Y and Guo L 2018 Design and facile synthesis of mesoporous cobalt nitride nanosheets modified by pyrolytic carbon for the nonenzymatic glucose detection Sens. Actuat. B: Chem. 2551983

37. Gao D, Zhang J, Wang T, Xiao W and Tao K 2016 Metallic $\mathrm{Ni}_{3} \mathrm{~N}$ nanosheets with exposed active surface sites for efficient hydrogen evolution J. Mater. Chem. A 417363

38. Xiao C, Li S, Zhang X and MacFarlane D R 2017 $\mathrm{MnO}_{2} / \mathrm{MnCO}_{2} \mathrm{O}_{4} / \mathrm{Ni}$ heterostructure with quadruple hierarchy: a bifunctional electrode architecture for overall urea oxidation J. Mater. Chem. A 57825

39. Chen S, Duan J, Ran J, Jaroniec M and Qiao S 2013 Ndoped graphene film-confined nickel nanoparticles as a highly efficient three-dimensional oxygen evolution electrocatalyst Energy Environ. Sci. 63693

40. Lu X and Zhao C 2015 Electrodeposition of hierarchically structured three-dimensional nickel-iron electrodes for efficient oxygen evolution at high current densities Nat. Commun. 66616

41. Liu D, Liu T, Zhang L, Qu F, Du G, Asiri A M and Sun X 2017 High-performance urea electrolysis towards less energy-intensive electrochemical hydrogen production using a bifunctional catalyst electrode J. Mater. Chem. A 53208 